\title{
Species as Historical Individuals
}

\author{
ARNOLD G. KLUGE \\ Museum of Zoology and Department of Biology \\ University of Michigan \\ Ann Arbor, Michigan 48109 \\ U.S.A.
}

\begin{abstract}
The species category is defined as the smallest historical individual within which there is a parental pattern of ancestry and descent. The use of historical individual in this definition is consistent with the prevailing notion that species per se are not involved in processes - they are effects, not effectors. Reproductive isolation distinguishes biparental historical species from their parts, and it provides a basis for understanding the nature of the evidence used to discover historical individuals.
\end{abstract}

KEY WORDS: Phylogenetic systematics, reproductive isolation, species.

Species is one of the most important concepts in organismic biology. Reference to the species category or some binominal taxon, such as Homo sapiens, is commonplace, and some even consider species to be the unit of fundamental evolutionary significance (Eldredge 1985, p. 159; Howard 1988; Patterson 1988, p. 66). A species concept can be traced at least to Aristotle (Dewey 1910), and it has been debated vigorously from seemingly all perspectives: philosophical, operational, typological, populational and historical. The most recent discourse concerns the class-individual dichotomy (Ghiselin 1974; Hull 1978). It has been especially helpful because the species category is distinguished as a class from particular species which are instances of that kind (see, however, Rieppel 1986; Cracraft 1987, p. 343; Mishler and Brandon 1989).

Still, the species problem persists, and it is complicated by: (1) confusing the ontological status of species with how to individuate species operationally; (2) disagreeing over the role species play in evolutionaryecological theory; (3) applying different species concepts to biparental and uniparental organisms; (4) and insisting on applying the rule of monophyly to all species. The first three topics are reviewed in the body of the text to follow; the fourth complication is considered only in Notes 1, 3, 5 and 8 (see also Kluge 1989a).

\section{BIOLOGICAL AND PHYLOGENETIC SPECIES CONCEPTS}

The prevailing opinion is that genealogical taxonomies must be restricted 
to individuals because only they have history (Cracraft 1987, p. 351; Frost and Wright 1988, p. 201). For example, Mishler and Donoghue (1982), Cracraft (1983, 1987), Donoghue (1985), Mishler and Brandon (1987), and McKitrick and Zink (1988) reviewed the popular biological species concept (e.g., Mayr 1942, p. 120; "species are groups of actually or potentially interbreeding natural populations, which are reproductively isolated from other such groups"), and the principal problem they identified with that concept is that reproductive communities do not necessarily correspond to well corroborated clades. Such inconsistency seems to be especially true in plants (Chris Humphries, pers. comm.).

All the aforementioned reviewers argued for an alternative phylogenetic (evolutionary) species concept, which has three things in common: (1) empirically investigating species with a cladistic analysis of synapomorphies scored among individual organisms (where ideally organism means entire life-cycle) or local populations of interbreeding organisms (demes) as terminal taxa (e.g., Kluge 1969, 1988; de Queiroz and Donoghue 1988); (2) employing the rule of monophyly to achieve a consistent, genealogical taxonomy; ${ }^{1}$ (3) attributing the category species to one of the least inclusive clades "within which there is a parental pattern of ancestry and descent" (Cracraft 1983, p. 170).

According to Mishler and Donoghue (1982; see also Mishler and Brandon 1987, p. 406; 1989), the species category is "the smallest 'important' lineage deemed worthy of formal recognition, where 'important' refers to the action of those processes that are dominant in producing and maintaining lineages in a particular case." Donoghue (1985, p. 179) would simply give "species rank to the smallest recognizable monophyletic or unresolved units" (see also Rosen 1978, 1979; Nelson and Platnick 1981; Cracraft 1983, 1987; McKitrick and Zink 1988). Mishler and Donoghue's (1982; see also Mishler and Brandon 1987; de Queiroz and Donoghue 1988) treatment is unsatisfactory because the pluralistic solution they propose for the 'species problem' "is the 'null hypothesis' that we should attempt to refute" (Sober 1984a, p. 341; see also Ghiselin 1987, 1989; Frost and Wright 1988). I believe there are two reasons why Donoghue's (1985) position will not be accepted widely. As I will discuss in detail below, it does not take into account the fact that species are generally considered to be products of evolution (lineages), but not the units participating in processes (neither the replicators or interactors; Hull 1980). Secondly, as the smallest clade, the species category is likely to be trivialized by the large numbers of taxa that will be recognized, and such taxa are likely to be unstable nomenclatorially. Further, Ereshefsky (1989) has criticized all the current formulations of the phylogenetic species concept on the grounds that they teach us little about the nature of species. 


\section{SPECIES AS HISTORICAL INDIVIDUALS}

It is clear that species are not classes (e.g., Ghiselin 1974; Hull 1978, 1980; see, however, Nelson 1989a). Moreover, as noted above, the species-as-individuals perspective seems to be carrying the day (see also Sober 1984a; Ghiselin 1987, 1988; Hull 1987; Ridley, 1989). However, are species typical individuals?

Mishler and Brandon (1987; see also de Queiroz and Donoghue 1988) provided a recent review of the class-individual dichotomy in which they distinguished four conditions of individuality: (1) spatial boundaries, (2) temporal boundaries, (3) cohesion, and (4) integration. They pointed out (p. 399) that "the former [1-2] refer to 'patterns,' i.e., effects of biological processes, and the latter $[3-4 \mid$ refer directly to the action of processes" (see Cracraft 1989a, for a lengthy discussion of cohesion and integration). All of the more inclusive clades, such as higher monophyletic taxa, which might be given the categorical rank of genus, family, etc., are spatiotemporally restricted; however, processes of cohesion and integration have not been associated convincingly with those groups. According to Cracraft (1989a, p. 42), "the only evidence for suggesting that 'cohesive processes' might be operable is the temporal and spatial continuity of a particular pattern of character variation. The reality of one or more 'cohesive processes' is another question altogether." To be sure, the congruent synapomorphies exhibited by higher taxa might be interpreted as circumstantial evidence of cohesion, a "sticky" process (Eldredge 1985), but common ancestry explains the presence of shared apomorphies equally well (de Queiroz and Donoghue 1988). Thus, as Ghiselin (1987, p. 141) succinctly summarized our current understanding, "genera and higher taxa never do anything."

In contrast to higher taxa, all four conditions of individuality apply to demes. While the unity of demes is obviously a function of the action of cohesive and integrative processes, such as mating and reproduction, demes are also spatiotemporally restricted, if only for relatively short periods of time (Figure 1b, c). Perhaps our best examples of individuals are organisms (Hull 1978).

Wiley $(1981 \mathrm{~b}$, pp. 74-76) referred to higher monophyletic taxa as "historical groups" because only the two conditions of pattern apply. I believe an equally strong case can be made for considering species taxa to be historical groups. In the remainder of this paper, I refer to any monophyletic taxon that is not involved in processes as a historical individual; the term contemporary individual is reserved for those entities that are spatiotemporally restricted and are directly involved in cohesive and integrative processes (other terms have been used by Hull 1978; and Wiley 1980, 1981b). As a rule, according to Cracraft (1989a), if the 
actions of an individual can be ascribed to the additive actions of included, smaller, units of diversity then that individual is termed historical.

The category species, as a class concept, is defined. Moreover, as Ghiselin (1988, pp. 468-469; see also Cracraft 1989a, p. 44) stated, "what individuals populate the world and what roles they play in evolution and other processes are empirical questions to be answered by reference to the data of experience." Therefore, it is appropriate to summarize common knowledge pertaining to species (a more detailed review will be presented in Kluge, ms.) before defining the species category. For example, biparental species are viewed generally as forming lineages (Figure 1), and I think it is fair to say that biparental species are also understood to be polymorphic (Figure 2; Hennig 1966, Figure 6), and often polytypic when geographically widespread (Hull 1980, p. 324). Rarely is a single, uniform deme referred to as a species. Also, only five classes of processes seem to have been attributed frequently to species: evolution (anagenesis), speciation (cladogenesis), extinction, dispersal, and ecological interactions, such as competition (Ghiselin 1987; Cracraft 1989a).

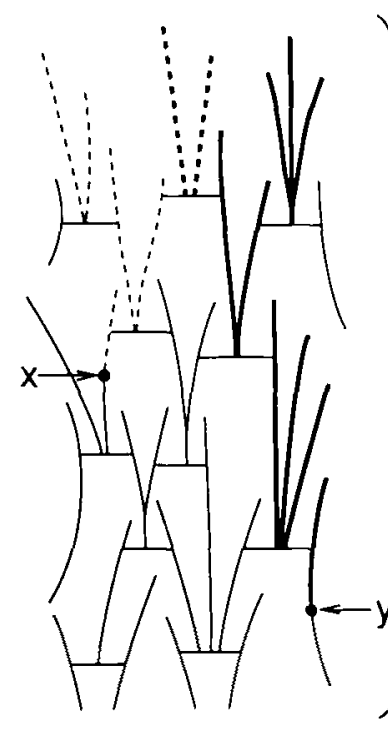

a

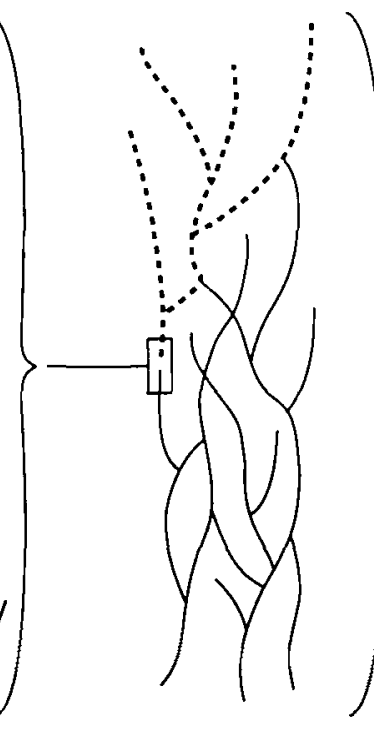

b

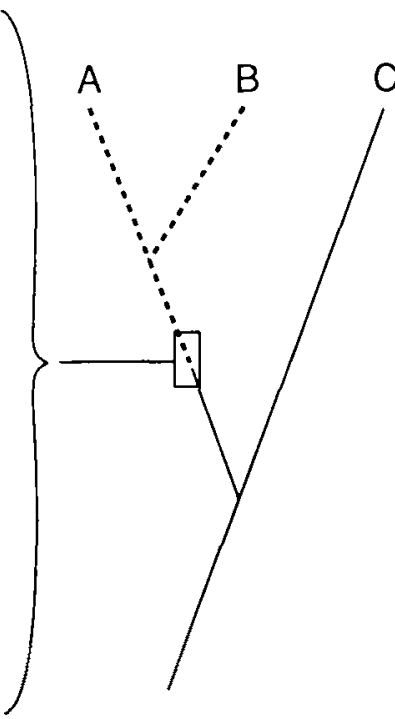

C

Fig. 1. The relationship between anagenesis and cladogenesis in biparental organisms. (a) Two novelties ( $x$ and $y$ ) originate independently, and spread among the parts of a deme. A horizontal line denotes mating; a vertical line symbolizes an organism's ontogeny from conception to death. (b) The novelties spread among demes. The coalescing lines depict the temporary nature of demes, due to dispersal of organisms or the union of entire reproductive communities. (c) The novelties cannot spread beyond the bounds of reproductively isolated lineages. Modified after Simpson (1955, Figure 48). 


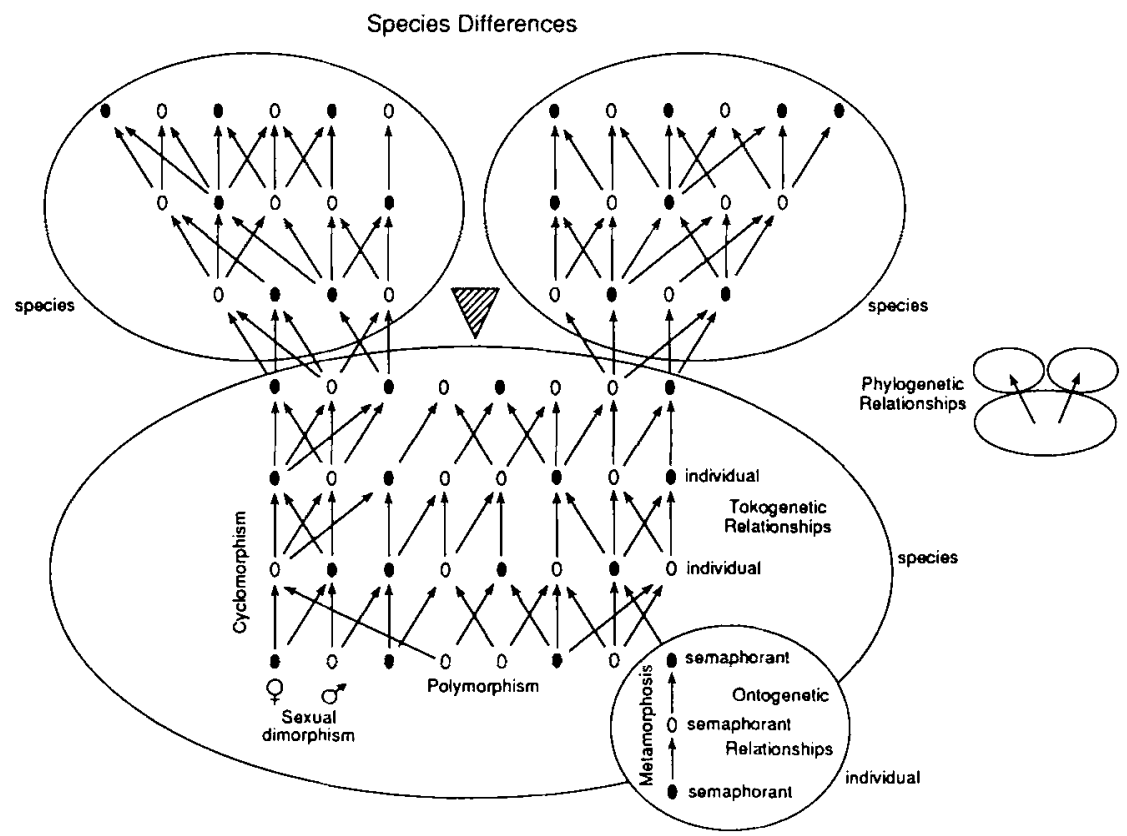

Fig. 2. "The total structure of hologenetic relationships and the differences in form associated with its individual parts" (Hennig 1966, p. 31). Modified after Hennig (1966, Figure 6).

Lewontin (1970) outlined the few conditions necessary and sufficient for evolution by natural selection, and he recognized species as one of the units in the traditional organizational hierarchy that could possibly be involved in that process. However, Hull (1980; see also Damuth 1985) concluded that species is an unlikely candidate because the necessary conditions of replication and interaction do not seem to apply to that unit. $^{2}$ Various group selection arguments and examples (e.g., Stanley 1975; Jablonski 1987) have been examined, and none appears to be convincing (Levinton 1988; Russell and Lindberg 1988). The same conclusion pertains to species adaptations; while possible, they don't appear to apply (Williams 1966; Sober 1984b). Vrba's (1980) effect hypothesis, which does not assume adaptation (Schoch 1986), seems to have fared no better in explaining interspecific "macroevolutionary" patterns (Damuth and Heisler 1988).

The familiar notion of new species originating from ancestral species by anagenesis alone, the non-lineage concept of speciation held commonly by paleontologists (see, however, Gauthier et al. 1988), might also suggest a process in which species per se are participants. However, upon close inspection all the examples of common ancestral species seem to be 
ambiguous (e.g., the stratophenetic common ancestors of Gingerich 1979), or the common ancestors can be described more simply as parts of species (i.e., individual organisms or demes; Mishler and Brandon 1987, p. 409).

What then is speciation? According to Hennig (1966, Figure 6; see also Futuyma 1987, p. 467), in biparental organisms it is the production of inherently hierarchical lineages. Further, the ancestry of such historical individuals is to be found among the parts of species, not among species per se, and the patterns of parent-offspring relationship (tokogenetic) at that level are inherently non-hierarchical (Cracraft 1989a, p. 49). ${ }^{3}$ Cracraft (1983, pp. 174-184, 1989b; see also Wiley 1981b) discussed novel ways to begin studying speciation (sensu Hennig's model). They involve assessing areas of endemism and their congruence, with the objective of distinguishing between dispersal and vicariance hypotheses (Kluge 1989b). In contrast, the populational view of speciation, that which accompanies the biological species concept, involves hypotheses of future evolution - the actuality or potentiality of interbreeding (Darrel Frost, pers. comm.), which may explain why generalizations about populational speciation have been so difficult to discover (e.g., Barigozzi 1982; Vrba 1985). Although our current understanding may be preliminary and imperfect, speciation is sufficient to explain the origin of the diversity subsumed by all higher monophyletic taxa (Nelson 1989a). As Hennig (1981, p. 4) stated "All recent species are the physical descendants of ancient species, and so as we go back further into the past we are bound to encounter species that have given rise to more and more extensive groups of recent species."

Usually, contemporary individuals are actually involved when species extinction, dispersal and ecological interactions are considered. Indeed, it is rare that all parts of a species go extinct at once; the causes of extinction tend to be local, not global, phenomena. Individual organisms may be expected to disperse, but it is rare that a whole species moves in a singular manner (Kluge 1989b). To say that species compete (parasitize, predate, etc.) seems to be even more of an overstatement. For example, Margalef (1968) argued convincingly that species do not have anything that could be considered a unitary ecology, and the competing entities are likely to be semaphoronts (Hennig 1966). Even the process of competing reproductively, which Ghiselin (1974) attributed to species, seems to be more accurately understood as an epiphenomenon on individual effects (Ruse 1987). In summary, except for geographically restricted monotypic taxa, species do not appear to participate directly in evolutionary and ecological processes, only their parts do. As such, species usually do not act as cohesive wholes (see also Cracraft 1989a; Ereschefsky, ms.).

Now, the question may be raised as to why the species category should not be defined as the smallest clade. In the preceding discussion I distinguished between historical and contemporary individuals, and concluded 
that species are examples of the former. Nonetheless, contemporary individuals, such as demes, have been diagnosed on occasion, and such delimitations may be expected to increase with the discovery of new molecular techniques. In those instances, the smallest clade would be too small for species, as historical individuals (Futuyma 1987, p. 467). Further, greater taxonomic instability is expected when contemporary individuals, such as demes, are equated with species taxa than when the chosen entities are historical individuals. There appear to be two reasons for the instability: (1) evidence of history may be difficult to discover because of the "microevolutionary" nature of novelties (continuous and polymorphic variations; Arnold 1981, pp. 16-19); (2) incompletely isolated lineages tend to generate homoplasy (e.g., incongruence due to segregation and recombination) and unresolved hypotheses of taxonomic relationships result because of conflicting character evidence. Species as the smallest clade will greatly increase the number of species taxa, but that does not necessarily mean there will be an improved understanding of pattern and process (contra Cracraft $1989 \mathrm{~b}$ ). The quality and the amount of the evidence on which our phylogenetic hypotheses are based must also be taken into consideration.

Thus, I define the species category as the class whose members are the smallest historical individuals within which there is a parental pattern of ancestry and descent. ${ }^{4}$ Operationally, particular species, like other historical groups, are delimited with synapomorphies; recognition of species is not a matter of having a defining property or set of properties (contra Nelson and Platnick 1981). My definition of the species category emphasizes Hennig's (1966) view that there is a break at the species level, with reticulating genealogical relationships predominating among the parts of a species, but not among species (Figure 2). Under my definition, species are real, at least as much as any monophyletic higher taxonomic hypothesis is real, but species are probably not the fundamental unit of evolution neither replicator or interactor. According to Cracraft (1989a, p. 50), "Species are much like developmental pathways within the ontogeny of individual organisms: both are effects rather than effectors. They are epiphenomena, developed or evolved from lower-level processes. Both are thus historical entities or 'by-products'."

Does the species category become less important when defined as a historical individual? In one sense it does, but in another it does not. With few exceptions, species can be no longer viewed as the players in the evolutionary and ecological theatre (Kawata 1987, p. 419), and consequently we lose the opportunity to formulate natural laws about the class species in those contexts. Nonetheless, species are the lineages which change indefinitely through time as the result of those processes (Hull 1980 , p. 327), and laws remain to be discovered at lower, populationorganism, levels (Ghiselin 1988). At least conceptually, species, as the 
smallest historical individuals, will be the same among clades, and such a conceptualization provides a comparable unit with which taxonomic diversity might be studied quantitatively. Moreover, my definition requires that pattern be distinguished from process, and in that regard I believe our understanding of the nature of diversity will improve. Any definition that confounds the two will surely lead to misunderstanding.

\section{REPRODUCTIVE ISOLATION}

I agree that reproductive isolation should not be a part of a species definition (McKitrick and Zink 1988, pp. 5, 8; see also Mishler and Donoghue 1982 , p. 498 ) because reproductive isolation and the cladistic hierarchy may not be perfectly correlated (Figure 3). However, I argue that reproductive isolation is an important relation (not interbreeding) in distinguishing historical from contemporary individuals (see also McKitrick and Zink 1988; Ridley 1989), ${ }^{5}$ and it provides a basis for understanding the nature of the evidence used to discover historical groups. Mayr (1963; see also Cracraft 1983, p. 163; Eldredge 1985) also recognized explicitly many years ago the general importance of reproductive isolation. Mayr stated (p. 31) that "the primary criterion of species rank of a natural population is reproductive isolation. The degree of morphological difference displayed by a natural population is a by-product of the genetic discontinuity resulting from reproductive isolation." (I assume Mayr's "degree of morphological difference" can be equated to number of
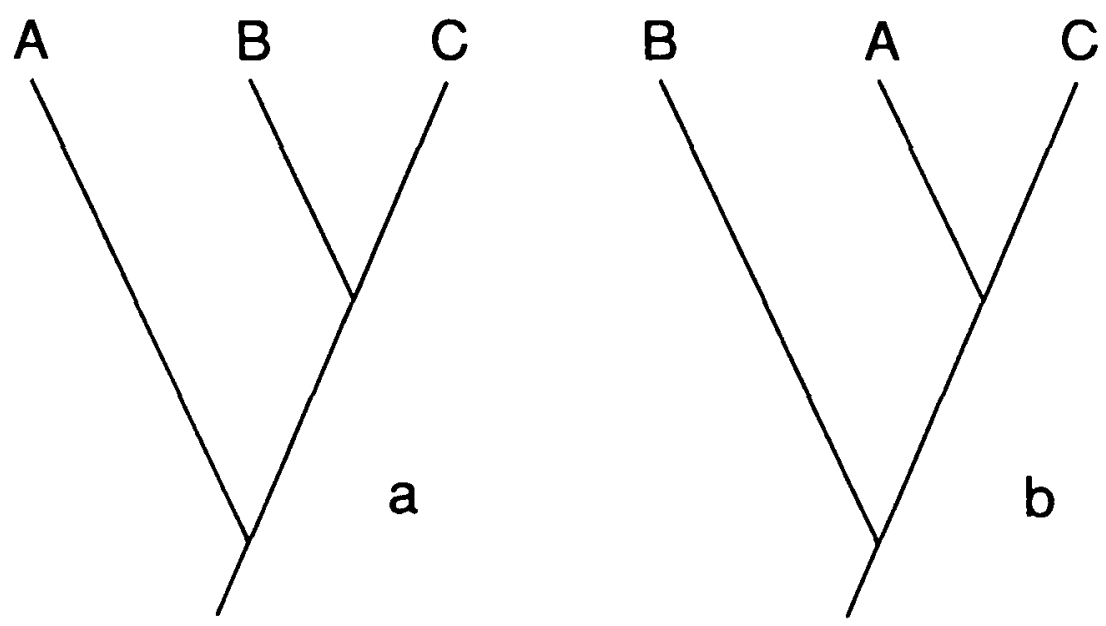

Fig. 3. (a) The true phylogeny. (b) The pattern of relationships based on interbreeding (taxa $\mathrm{A}$ and $\mathrm{C}$ interbreed, but neither does with B). Modified after McKitrick and Zink (1988, Figure 1). 
congruent synapomorphies.) Still, the parts of a species may not have anything in common but reproductive isolation.

Admittedly, divergence and reproductive isolation are nof perfectly coupled because the former can occur in the absence of the latter, i.e., in the context of geographic isolation alone. As Cracraft (1989a, p. 53) pointed out, "all reproductive isolation manifests differentiation, but not all differentiation is manifested as reproductive isolation." Also, as noted above, the least inclusive clade can be reproductively isolated, but that does not mean more plesiomorphic sister taxa are reproductively isolated from each other (Figure 3; McKitrick and Zink 1988, p. 8). Still, reproductive isolation is the only process that guarantees, for the indeterminate future, the individuality of lineages of organisms; geographic isolation by itself does not (Futuyma 1987, p. 467). As Mishler and Donoghue (1982, p. 495) stated, "the importance of reproductive barriers is that groups that are reproductively isolated for long periods of time are at least evolutionarily independent (whether or not they diverge morphologically), making them effectively separate entities." It is in this way that reproductive isolation and historical individuality are connected. A more limited species concept that defines species only as the smallest clade (e.g., Cracraft 1983; Donoghue 1985) does not distinguish reproductively and geographically isolated individuals.

The shared traits that provide systematists with evidence of sister group relationships are assumed to originate by mutation and/or recombination (Figure 1a). The taxonomic generality of traits is affected proximally by interbreeding and/or reproduction, and ultimately by reproductive isolation. The first two processes account for the increased appearance of a novelty, horizontally and vertically (Figure 1a), while the last stops its spread. In biparental organisms, interdemic geographic isolation (Figure 1b) tends to retard the diffusion process of traits, but only reproductive isolation actually confines it (Figure 1c). It is in this way that divergence, levels of character generality, and reproductive isolation are connected.

There seem to be three possible explanations for the presence of synapomorphies at the same level of taxonomic generality: lack of character independence, sampling artifact, and reproductive isolation. Processes such as genetic linkage can produce similar patterns of character covariation; however, systematists do not knowingly use such characters in assessing clades because they are not independent evidence of history (Kluge 1989c). Likewise, failure to sample all lineages, extant or extinct, can be viewed as a methodological problem over which the investigator has some control. The effect of reproductive isolation is another matter the length of time a lineage of biparental organisms is isolated and the effectiveness of the isolation being the critical parameters. That is, two or more novelties that appear independently in different parts of a reproductive community (Figure 1a) will in time proceed to the same limit set by 
reproductive isolation (Figure 1c). ${ }^{6}$ Such exact character congruence (confirmation) might be useful in operationalizing my species-as-historicalindividual definition because it implies the presence of effective isolation and historical individuality. Also, emphasizing corroborated taxa ensures some measure of taxonomic stability, sensu the spatiotemporal limits of the hypothesized historical entities.

Mishler and Brandon's (1987, p. 397; see also de Queiroz and Donoghue 1988) ranking criterion of species is pluralistic, in the sense that whatever causal processes are deemed "most important in producing and maintaining lineages in a particular case" are to be employed. My definition of the species category is monistic; however, there is more than one way it can be operationalized. For example, application of Nelson's (1983) cladistic methodology for discovering hybrids might suggest the presence of ineffective isolation, and the categorical rank of species would then be attributed to a more inclusive clade, one that does not appear to be involved in hybridization. Abrupt changes in a homoplasy profile ${ }^{7}$ (Kluge 1971) might also be used to adjust the rank of species to a larger clade. It is worth noting that hybridization and homoplasy analyses provide estimates of cohesion and integration (see Mishler and Brandon 1987, pp. 399-400). Also, both analyses employ the same evidential basis used to discover the groups in the first place (synapomorphies as putative homologues), and in that sense the importance of those analyses in adjusting the rank of species follows from cladistic principles. Systematists interested in species per se might also search for apomorphies that are causally connected to reproductive isolating mechanisms (including specific mate recognition characters, sensu Paterson, 1985; see also Coyne et al. 1988, p. 193), and those apomorphies could be used to assemble demes into clades. Thus, additional importance may be attached to my particular monistic view of the species category because it is part of a larger coherent theory, phylogenetic systematics (Mishler and Donoghue 1982 , p. 495). Of course, the simplest operational context is to observe parts of sister lineages in sympatry, which would be considered prima facie evidence for reproductive closure and historical individuality.

\section{UNIPARENTAL SPECIES}

The preceding discussions of the phylogenetic species concept, species-ashistorical-individual definition, and reproductive isolation are couched in terms of biparental organisms, and greater generality would obtain if my ideas also applied to uniparentals. To begin with, there is no reason to believe that uniparentals can't be analyzed cladistically, even though they don't form lineages (sensu Hull 1980), and there is evidence that uniparental and biparental taxa exhibit similar unity (Mishler 1985). In the 
absense of horizontal transfer of novelties, one might expect to find numerous large polytomies relatively more frequently in uniparentals. Still, there should be no more difficulty applying the rule of monophyly to uniparentals than to biparentals because that convention is blind to sexuality. Further, clades of uniparental organisms are historical individuals, like higher taxa, because according to Ghiselin (1987, p. 141) "they don't do anything either." Therefore, a uniparental species would be the smallest clade, and as historical individuals, uniparental species are no longer "pseudospecies" (Ghiselin 1987, p. 138; 1989). ${ }^{8}$

\section{ACKNOWLEDGEMENTS}

This paper was prepared for Brent Mishler's symposium on species, held at the Stockholm meetings of the Willi Hennig Society, 1988, which I was unable to attend. I thank Doug Begle, Paulo Buckup, Chris Humphries, Michael Donoghue, Doug Eernisse, Marc Ereshefsky, Darrel Frost, Michael Ghiselin, David Hillis, Fred Kraus, Mary McKitrick, Brent Mishler, William Moore, Elliott Sober, Priscilla Tucker, Dick VaneWright, and Ed Wiley for reading one or more of the early drafts of the manuscript. Their criticisms helped to sharpen my arguments; however, I assume sole responsibility for all those errors and ambiguities that remain. This investigation was supported in part by N. S. F. grant BSR-8822656.

\section{NOTES}

' The monophyly convention ensures that taxonomies are complete systems of sister group relationships, where each such system contains all the descendants of the most recent common ancestor of the system. Thus, monophyly achieves logically consistent phylogenetic hypotheses and taxonomies (Hull 1964; Wiley 1981a), which is viewed by some as the cornerstone of cladistics (Nelson 1989a; see, however, Note 3). Like Nelson (1989b), I see no purpose in considering monophylysis to be a natural process (contra de Queiroz and Donoghue 1988; see also Mishler and Brandon 1987).

2 Ereshefsky (1988, p. 221; see, however, Cracraft 1989a, p. 43) has argued that "the individuality of a group is neither necessary nor sufficient for its being a unit of selection", and "that the individuality of a species is neither necessary nor sufficient for the truth of the Theory of Punctuated Equilibrium."

${ }^{3}$ It is widely held that species evolve from other species, and this means that species taxa can't all be required to be monophyletic. Thus, in the phylogenetic system all monophyletic taxa are hypothesized individuals, but not all individuals can be monophyletic (contra Rowe 1987 , p. 210 ). Hennig understood this asymmetry perfectly $(1981$, p. 29). That ancestral species can't be monophyletic should present few if any practical problems in taxonomy because ancestral species are difficult to individuate (Donoghue et al. 1989). In any case, special taxonomic conventions are available to flag non-monophyletic ancestral species taxa if they were to be discovered (Wiley 1981b; Kluge 1989a).

4 My definition of species is similar to Simpson's (1961; see also Wiley 1978) - "an 
evolutionary species is a lineage (an ancestral-descendant sequence of populations) evolving separately from others and with its own unitary evolutionary role and tendencies." However, the conceptual contexts in which the definitions are developed are quite different (Frost and Hillis 1989).

5 Donoghue's (1985) metaspecies and Wiley's (1981b) sedis mutabilis conventions can be used to distinguish non-monophyletic species taxa when the terminal taxa, individual organisms or demes, form unresolved plesiomorphic sister assemblages (Kluge 1989b).

${ }^{\circ}$ This of course assumes that geographic isolation within a reproductive community is only temporary.

7 Homoplasy is assumed to be greater among the organisms and demes within a reproductively isolated lineage than it is among reproductively isolated lineages because reproductive closure necessarily limits the amount of homoplasy that can result from independent segregation and recombination.

${ }^{8}$ Special problems in the taxonomy of uniparentals are reviewed by Frost and Wright (1988; see also Echelle 1990).

\section{REFERENCES}

Arnold, E. N.: 1981, 'Estimating Phylogenies at Low Taxonomic Levels', Zeitschrift für zoologische Systematik und Evolutionsforschung 19, 1-35.

Barigozzi, C. (ed.): 1982, Mechanisms of Speciation, Liss, New York.

Coyne, J. A., H. A. Orr, and D. J. Futuyma: 1988, 'Do We Need a New Species Concept?' Systematic Zoology 37, 190-200.

Cracraft, J.: 1983, 'Species Concepts and Speciation Analysis', in R. F. Johnston, Current Ornithology 1, Plenum Press, New York, pp. 159-187.

Cracraft, J.: 1987, 'Species Concepts and the Ontology of Evolution', Biology and Philosophy 2, 329-346.

Cracraft, J.: 1989a, 'Species as Entities of Biological Theory', in M. Ruse, What the Philosophy of Biology Is - Essays for David Hull, Kluwer, Netherlands, pp. 33-54.

Cracraft, J.: 1989b, 'Speciation and Its Ontology: The Empirical Consequences of Alternative Species Concepts for Understanding Patterns and Processes of Differentiation', in D. Otte and J. A. Endler, Speciation and Its Consequences, Sinauer, Sunderland, Massachusetts, pp. 28-59.

Damuth, J.: 1985, 'Selection among 'Species': A Formulation in Terms of Natural Functional Unit', Evolution 39, 1132-1146.

Damuth, J. and I. L. Heisler: 1988, 'Alternative Formulations of Multilevel Selection', Biology and Philosophy 3, 407-430.

de Queiroz, K. and M. J. Donoghue: 1988, 'Phylogenetic Systematics and the Species Problem', Cladistics 4, 317-338.

Dewey, J.: 1910, The Influence of Darwin on Philosophy and Other Essays in Contemporary Thought, Holt, New York.

Donoghue, M. J.: 1985, 'A Critique of the Biological Species Concept and Recommendations for a Phylogenetic Alternative', Bryologist 88, 172-181.

Donoghue, M. J., J. A. Doyle, J. Gauthier, A. G. Kluge, and T. Rowe: 1989, 'The Importance of Fossils in Phylogeny Reconstruction', Annual Review of Ecology and Systematics 20, 431-460.

Echelle, A. A.: 1990, 'Nomenclature and Non-Mendelian ("Clonal") Vertebrates', Systematic Zoology 39, 70-78.

Eldredge, N.: 1985, Unfinished Synthesis. Biological Hierarchies and Modern Evolutionary Thought, Oxford University Press, New York.

Ereschefsky, M.: 1988, 'Individuality and Macroevolutionary Theory', Philosophy of Science Association 1, 216-222. 
Ereschefsky, M.: 1989, 'Where's the Species? Comments on the Phylogenetic Species Concepts', Biology and Philosophy 4, 89-96.

Ereschefsky, M.: ms. 'Species, Higher Taxa, and the Units of Evolution', submitted.

Frost, D. R. and D. M. Hillis: 1989, 'Species in Concept and Practice: Herpetological Applications', Herpetological 46, 87-104.

Frost, D. R. and J. W. Wright: 1988, 'The Taxonomy of Uniparental Species, with Special Reference to Parthenogenetic Cnemidophorus (Squamata: Teiidae)', Systematic Zoology 37, 200-209.

Futuyma, D. J.: 1987, 'On the role of Species in Anagenesis', American Naturalist 130, $465-473$.

Gauthier, J., A. G. Kluge, and T. Rowe: 1988, 'Amniote Phylogeny and the Importance of Fossils', Cladistics 4, 105-209.

Ghiselin, M. J.: 1974, 'A Radical Solution to the Species Problem', Systematic Zoology 23 , $536-544$.

Ghiselin, M. J.: 1987, 'Species Concepts, Individuality, and Objectivity', Biology and Philosophy 2, 127-143.

Ghiselin, M. J.: 1988, 'The Individuality Thesis, Essences, and Laws of Nature', Biology and Philosophy 3, 467-474.

Ghiselin, M. J.: 1989, 'Sex and the Individuality of Species: A Reply to Mishler and Brandon', Biology and Philosophy 4, 73-76.

Gingerich, P. D.: 1979, 'The Stratophenetic Approach to Phylogeny Reconstruction in Vertebrate Paleontology', in J. Cracraft and N. Eldredge, Phylogenetic Analysis and Paleontology, Columbia University Press, New York, pp. 41-77.

Hennig, W.: 1966, Phylogenetic Systematics, University of Illinois Press, Chicago.

Hennig, W.: 1981, Insect Phylogeny, Wiley, New York.

Howard, D. J.: 1988, 'The Species Problem', Evolution 42, 1111-1112.

Hull, D. L.: 1964, 'Consistency and Monophyly', Systematic Zoology 13, 1-11.

Hull, D. L.: 1978, 'A Matter of Individuality', Philosophy of Science 45, 335-360.

Hull, D. L.: 1980, 'Individuality and Selection', Annual Review of Ecology and Systematics $11,311-332$.

Hull, D. L.: 1987, 'Genealogical Actors in Ecological Roles', Biology and Philosophy 2, $168-184$.

Jablonski, D.: 1987, 'Heritability at the Species Level: Analysis of Geographic Ranges of Cretaceous Mollusks', Science 238, 360-363.

Kawata, M.: 1987, 'Units and Passages: A View for Evolutionary Biology and Ecology, Biology and Philosophy 2, 415-434.

Kluge, A. G.: 1969, 'The Evolution and Geographical Origin of the New World Hemidactylus mabouia-brookii Complex (Gekkonidae, Sauria)', Miscellaneous Publications, Museum of Zoology, University of Michigan, No. 138, 1-78.

Kluge, A. G.: 1971, 'A Quantitative Approach to the Biological Species Concept', American Philosophical Society Year Book 1971, 329-333.

Kluge, A. G.: 1988, 'the Characterization of Ontogeny', in C. J. Humphries, Ontogeny and Systematics, Columbia Univeristy Press, New York, pp. 57-81.

Kluge, A. G.: 1989a, 'Metacladistics', Cladistics 5, 291-294.

Kluge, A. G.: 1989b, 'Parsimony in Vicariance Biogeography: A Quantitative Method and a Greater Antillean Example', Systematic Zoology 37, 315-328.

Kluge, A. G.: 1989c, 'A Concern for Evidence and a Phylogenetic Hypothesis of Relationships among Epicrates (Boidae, Serpentes)', Systematic Zoology 38, 7-25.

Kluge, A. G.: ms. 'Species Theories from Aristotle to Cladistics', in preparation.

Levinton, J.: 1988, Genetics, Paleontology, and Macroevolution, Cambridge University Press, New York.

Lewtonin, R. C.: 1970, 'The Units of Selection', Annual Review of Ecology and Systematics $1,1-18$. 
Margalef, R.: 1968, Perspectives in Ecological Theory, University of Chicago Press, Chicago.

Mayr, E.: 1942, Systematics and the Origin of Species, Columbia University Press, New York.

Mayr, E.: 1963, Animal Species and Evolution, Harvard University Press, Cambridge, Massachusetts.

McKitrick, M. C. and R. M. Zink: 1988, 'Species Concepts in Ornithology', Condor 90, $1-14$.

Mishler, B. D.: 1985, 'The Morphological, Developmental, and Phylogenetic Basis of Species Concepts in Bryophytes', Bryologist 88, 207-214.

Mishler, B. D. and R. N. Brandon: 1987, 'Individuality, Pluralism, and the Phylogenetic Species Concept', Biology and Philosophy 2, 397-414.

Mishler, B. D. and R. N. Brandon: 1989, 'Sex and the Individulity of Species: A Response to Ghiselin', Biology and Philosophy 4, 77-79.

Mishler, B. D. and M. J. Donoghue: 1982, 'Species Concepts: A Case for Pluralism', Systematic Zoology 31, 491-503.

Nelson, G.: 1983, 'Reticulation in Cladograms', in N. I. Platnick and V. Funk, Advances in Cladistics II, Columbia University Press, New York, pp. 105-114.

Nelson, G.: 1989a, 'Species and Taxa: Systematics and Evolution', in D. Otte and J. A. Endler, Speciation and lts Consequences, Sinauer, Sunderland, Massachusetts, pp. 6084.

Nelson, G.: 1989b, 'Cladistics and Evolutionary Models', Cladistics 5, 275-289.

Nelson, G.: and N. I. Platnick: 1981, Systematics and Biogeography: Cladistics and Vicariance, Columbia University Press, New York.

Paterson, H. E. H.: 1985, 'The Recognition Concept of Species', in E. S. Vrba, Species and Speciation, Transvaal Museum Monograph, No. 4, Transvaal Museum, Pretoria, pp. $21-29$.

Patterson, C.: 1988, 'The Impact of Evolutionary Theories on Systematics,' in D. L. Hawksworth, Prospects in Systematics. Systematics Association Special Volume, No. 36. Oxford University Press, Oxford, pp. 59-91.

Ridley, M.: 1989, 'The Cladistic Solution to the Species Problem', Biology and Philosophy 4, $1-16$.

Rieppel, O.: 1986, 'Species Are Individuals: A Review and Critique of the Argument, Evolutionary Biology 20, 283-317.

Rosen, D. E.: 1978, 'Vicariant Patterns and Historical Explanation in Biogeography', Systematic Zoology 27, 159-188.

Rosen, D. E.: 1979, 'Fishes from the Uplands and Intermontane Basin of Guatemala: Revisionary Studies and Comparative Geography', Bulletin of the American Museum of Natural History $162,267-376$.

Rowe, T.: 1987, 'Definition and Diagnosis in the Phylogenetic System'. Systematic Zoology 36, 208-211.

Ruse, M.: 1987, 'Biological Species: Natural Kinds, Individuals, or What?'. British Journal for the Philosophy of Science 38, 225-242.

Russell, M. P. and D. R. Lindberg: 1988, 'Real and Random Patterns Associated with Molluscan Spatial and Temporal Distributions', Paleobiology 14, 322-330.

Schoch, R. M.: 1986, Phylogeny Reconstruction in Paleontology, Van Nostrand Reinhold, New York.

Simpson, G. G.: 1955, The Major Features of Evolution, Columbia University Press, New York.

Simpson, G. G.: 1961, Principles of Animal Taxonomy, Columbia University Press, New York.

Sober, E.: 1984a, 'Sets, Species, and Evolution: Comments on Philip Kitcher's "Species", Philosophy of Science 51, 334-341. 
Sober, E.: 1984b, The Nature of Selection. Evolutionary Theory in Philosophical Focus, MIT Press, Cambridge, Massachusetts.

Stanley, S.: 1975, 'A Theory of Evolution above the Species Level', Proceedings of the National Academy of Science 72, 646-650.

Vrba, E. S.: 1980, 'Evolution, Species and Fossils: How Does Life Evolve?’, South African Journal of Science 76, 6!-84.

Vrba, E. S. (ed.): 1985, Species and Speciation. Transvaal Museum Monograph, No. 4, Transvaal Museum. Pretoria.

Wiley, E. O.: 1978, 'The Evolutionary Species Concept Reconsidered', Systematic Zoology $27,17-26$.

Wiley, E. O.: 1980, 'Is the Evolutionary Species Fiction? - A Consideration of Classes, Individuals, and Historical Entities', Systematic Zoology 29, 76-80.

Wiley, E. O.: 1981a, 'Convex Groups and Consistent Classifications', Systematic Botany 6, $346-358$.

Wiley, E. O.: 1981b, Phylogenetics: The Theory and Practice of Phylogenetic Systematics, Wiley, New York.

Williams, G. C.: 1966, Adaptation and Natural Selection: A Critique of Some Current Evoltutionary Thought, Princeton University Press, Princeton, New Jersey. 